\title{
IUELTAL
}

\section{Motivation for Participating and Performing in English Classrooms: Between Self-images and Positioning}

\author{
Shanthi Nadarajan \\ Universiti Malaysia Sarawak \\ e-mail:nshanthi@unimas.my \\ Nurulhuzaiman Hussain \\ Universiti Malaysia Sarawak \\ e-mail:hnhuzaimah@unimas.my \\ Damien Mikeng \\ Universiti Malaysia Sarawak \\ e-mail:mdamien@unimas.my
}

\begin{abstract}
:
Second language learning motivation is often analyzed as a multidimensional construct involving learner's images of their individual selves and complex statistical measures. While many of these analysis have deepened understanding of various cognitive and affective factors influencing language learner behavior, research investigating the different motivation factors that combine learner types remains scarce. Involving 78 Malaysian undergraduates from a University in East Malaysia taking a proficiency course, the study looked at learner motivation in relation to $L 2$ motivational dimensions, classroom factors and learning goals. An exploratory cluster analysis identified 4 group motivational profiles: 1-motivated, 2-amotivated, 3externally motivated and 4-self-determined. Initial data analysis found both learner images (the ideal L2 learner) and instrumental (Ought to L2 learner) as main factors influencing motivated learning behavior. The combined findings for learner confidence in the classroom and vitality of $L 2$ speaker communities revealed that except for the extrinsically motivated communities (e.g. International Finance students), most students indicated learning as more meaningful if attention was given to their first language resources. Classroom activities that integrate first language resources have a positive influence on learner's effort and willingness to invest while a strict L2-only perspective have a negative effect on learner motivation. Given
\end{abstract}


the role of English for the digital world, L2 universities may benefit from including learners' first language resources and experience for engaging and helping learners to perform academically. Keywords: cluster analysis, Malaysian English Learners, Second language motivation

\section{Introduction}

Developments in mainstream psychology and second language motivation research have contributed to better understanding of the complex nature of second language (L2) motivation. With language being a means of communication and an expression of identity, exploring English language learners (ELLs) learning behavior is useful due to its various benefits (Chew, 2010). As the language of the internet, international trade and business, English enables users to arrive at other socio-economic benefits. English also allows speakers to take on multiple identities as they communicate with speakers of other languages and this has contributed to an increase in demand for English language courses worldwide. Transposed to university English programs and educators responding to the proverbial chalk talk, this means greater accountability in terms of curricula, pedagogy and learner satisfaction (Behari-Leak, 2019). This study sets out to assess motivation factors that encourage sub communities within L2 communities to learn and perform.

L2 motivation is a dynamic and multifaceted construct and a variety of theories and approaches provide directions for interpreting the L2 learning process (Dornyei, 2005). L2 motivation differs from many psychological constructs due to the uneven process of language learning. Currently, three developments of the self, borrowed from mainstream psychology dominate L2 motivation research (Achugar, 2009). The first being, "identities are not given but developed, sustained and transformed through interaction" (Hopf, 2000, p.370). Transposed to the language classroom, ELLs like familiar settings where they play active roles. Positive positioning of learners through active learning give confidence to learners. Second, growing interest in the conceptualization of the self, such as "selfesteem" and "self-concept" and the inclusion of such conceptualizations into L2 motivation research (e.g. Dornyei, 2005; Noels et al., 2003) have contributed to various L2 motivation models. The L2 Motivational Self System (henceforth L2MSS) (Dornyei, 2005, 2009) with its three main components (e.g. the Ideal L2 self (IL2), Ought to L2 self (OL2) and Motivated learning behavior (MLB)) is able to assess the relationship between the main components and other emotional variables. However, the caveat being motivation research has often relied on self-reported questionnaires and complex statistical procedures (e.g. correlation, factor analysis and structural equation modeling) to study dominant motivational factors. These studies have deepened understanding of various cognitive and affective factors influencing language learners; but research looking at how different motivation factors combined in learner communities achieve specific learner types remain scarce (e.g. Csizer \& Dornyei, 2005). Third, given developments in technology, increasing ethnic nationalism and rising voices from the global south demanding a more inclusive university curricula, there is the need to reassess ELL sub communities' motivation for learning English. This study aims to address these gaps.

\section{Literature Review}

Research on individual difference (ID) in SLA have helped researchers identify dimensions of enduring $L 2$ characteristics applicable to all and on which individuals differ by degree. 
However, with L2 motivation being something that ELLs bring to the task and develop over time, exploring salient patterns in the motivational disposition of $L 2$ learners can shed meaningful light into the reality of $L 2$ learning. Presently, Dornyei's (2001) process model of learning and Noels, Pelletier, Clement and Vallerand's (2000) model of extrinsically motivated behavior and intrinsic motivation are used in classroom research to analyze learner motivation. The former looks at motivation in relation to learner's self-images and related motivational dimensions and the latter interprets external motivation along a continuum. It also describes the characteristics of self-determined learners. Dornyei's model is a psychological construct while Noels' model provides directions for a socio-psychological perspective.

\subsection{The motivation construct applied to the study}

Dornyei's (2009) L2MSS model comprises three main components namely the ideal L2 self (IL2), ought to $\mathrm{L}_{2}$ self $\left(\mathrm{O}_{2} \mathrm{~L}_{2}\right)$ and $\mathrm{L}_{2}$ learning experience. The IL2 (traditionally interpreted as "integrative motivation") is the $L 2$ specific facet of one's 'ideal self' and possess strong motivational functions as $L 2$ learners try to become the ideal person they have in mind (p.27). The $\mathrm{O}_{2} \mathrm{~L} 2$ refers to attributes learners belief one ought to possess to meet expectations and avoid possible negative outcomes. These attributes are present when learners try to avoid possible failures (e.g. examinations). The L2 learner experience concerns the context dependent impact of learners' perception of the atmosphere of the learning environment (e.g. classroom, teacher and university support). These components combined possess strong executive functions that mediate the impact of future self-guides (Papi, 2010). Dornyei and Csizer (2002) established L2 learners' generalized motivational variables based on seven components namely integrativeness, instrumentality, cultural interest, vitality of $\mathrm{L} 2$ community, milieu and linguistic self-confidence. Within these integrativeness (relabeled IL2) is determined by instrumentality and attitude. In this research, we shift the motivational variables to examine: a) the main factors affecting learner motivation based on L2 sub communities, and b) the relationship between learner types and the combined factors for interpreting positioning and investment The next section will explain a specific L2 sub community in an L2 setting before moving to the study.

\subsection{The Malaysian L2 Classroom Context}

In multilingual Malaysia, Malay is the national language and language spoken by the majority and English is the $L 2$ and language used in universities. In recent years, researchers have found considerable resentment among Malay learners towards the extended use of English (e.g. Lee et al., 2010). While it may appear unwise to argue any causal relationship between English language competency and a particular L2 sub-communities values, there is undoubtedly general unease at the slide towards intolerance, and ethnic conflicts that concerns both universities and public policies (Campbell, 2018) in Malaysia. This uneasy tension is often related to rising nationalistic sentiments and social awareness about economic equity and social justice. Then again, this does not mean total disregard for English as there are proficient Malay L2 learners with a positive view of English. Investigating the differences between these contrasting L2 learner types can contribute to better understanding successful L2 learner types. This issue is important for a typical Asian EFL/L2 setting where the mother tongue is used with English and learners generally lack environmental opportunities for actual target language use. 
Taken together, three research questions were proposed. The first question aims to: a) describe the main motivation factors influencing $L 2$ motivation, b) gauge the relationship learner types and combined traits, and c) determine the impact of combined traits that prompt L2 learner investment in English.

\section{Research Methodology}

\subsection{Population and Sample}

The study was an exploratory study involving 78 volunteers taking a complementary English course at a Malaysian public university. Only proficient English learners (MUET Band $4-5$ ) of Malay descent were selected from a population of 1200 students. There were $21(27 \%)$ males and $57(73 \%)$ females aged between 19 to 22 years. There were 34 students (44\%) from International Economics, 20 students (25\%) from Electronic Engineering and 24 students (31\%) from Resource Science.

\subsection{Instruments}

The theoretical framework from Dornyei's (2009) L2MSS was used. A 56 item adapted motivation questionnaire was used (e.g. Clement, Dornyei, \& Noels, 1994; Csizer \& Dornyei, 2005). Each item was assessed on a 6-point Likert scale. The instrument was organized around 7 subscales of motivational dimensions. The subscales were categorized as motivated learning experience $(\mathrm{ML})$, ideal $\mathrm{L}_{2}$ learner self $(\mathrm{IL} 2)$, Ought to $\mathrm{L}_{2}$ self $\left(\mathrm{O}_{2} \mathrm{~L} 2\right)$, Social Goals (SG), anxiety (ANX), performance goals (PG) and attitudes toward the L2 (ATT). The ILS, O2L2, SG, and ANX were key antecedents of the L2 motivational self-perceived future vision of the L2 learner; and motivated learning behavior was the target variable. The relevant Cronbach alpha coefficients were aligned with the number of items making up each scale (refer Table 1).

The ideal L2 self (IL2S): The Ideal L2 self-subscale comprised 8 items and the stems were modified (e.g. by adding "in a Malaysian university"). The main variable groups in the questionnaire were as follows:

1. Integrativeness/The Ideal L2 learner self (IL2- 8 items) - (e.g. reasons for learning English, attitudes towards the $L 2$, intended effort).

2. Ought to $\mathrm{L}_{2}$ learners ( $\mathrm{O}_{2} \mathrm{~L}_{2}-8$ items) - pressured to take the course for improving grades e.g., parental pressure, graduation requirement. These were considered as external regulatory factors.

3. Milieu/Social goals (SG-8 items) - extent of community support and peer group support.

4. Attitude towards the L2 community (Att-8 items) - extent to which students felt positively towards English, confidence, employability factors and contact with L2 speakers.

5. Anxiety (Anx-8 items) - extent to which learner is willing to participate in class, negativity

6. Effort (Efft-8 items) - extent to which learner is willing to invests, exert effort to succeed in the language

7. Motivated Learning Behavior (MLB- 8 items) -Target Output

Two additional dimensions namely anxiety and performance were assessed in a non L2 specific manner. Answering the online questions took approximately 20 minutes. 


\subsection{Data Analysis Procedures}

Cluster analysis was used to describe: a) distinct learner types based on specific patterns along the various L2 motivation dimensions, and to determine: b) the relationship between learner types and patterns affecting learner behavior in relation to positioning and investment. Clustering method was selected since it is a desirable alternative to factor analysis for data reduction with smaller sample sizes (Henry et al., 2005).

Basically five steps are involved in cluster analysis, namely (1) selection of a sample of individuals to be clustered, 2 ) definition of a set of variables used to measure the individuals in the sample, 3) computation of the similarities between the individuals, 4) use of a cluster analysis method to create groups of similar individuals and 5) interpretation of results. This involved hierarchical and non-hierarchical clustering. This was followed by a one-way multivariate analysis of variance used to determine differences between the independent factors on the overall scores. Screening for univariate and multivariate and outliers were conducted and internal consistency reliability (Cronbach's alpha) assessed. Descriptive statistics (e.g. means and standard deviations) and bivariate correlations were calculated to obtain a description of the sample. To identify motivation profiles, cluster analysis was conducted using the four motivation components namely MLB, IL2, $\mathrm{O}_{2} L 2$ and SG. Owing to the data driven nature of the study, two approaches were used to assess the stability of the motivation profiles as described in the results section.

To determine if there was profile groups difference for the L2MSS, a one-way ANOVA was conducted using the profile groups as the independent variable and the learners overall rating for questionnaire (Motivation Index). This enabled the data to be analyzed along a continuum. Next, an initial one-way MANOVA was conducted using the main factors (i.e., IL2, O2L2, and SG) as dependent variables. A second one-way MANOVA was also conducted using profile groups as the independent variable (i.e. anxiety, attitude) and constructs representing intrinsic motivation (i.e., effort in relation to knowledge, accomplishment, stimulation, teacher support and classroom) as dependent variables. Significant multivariate effects were followed up with univariate tests. Analysis was completed using SPSS 24. The mean, standard deviation, Cronbach's $\alpha$, and the correlations among the seven factors of the study are reported in Table 1 . All seven factors demonstrated good reliability (Cronbach $\alpha=.932-.831$ ). The data screening procedures did not identify any variables as non-normal (skewness/kurtosis $>2$ ), there were no univariate outliers $(z+3.0)$ and only three cases were identified as multivariate outliers (Mahalanobis D2 meeting a $p<.001$ criterion). Since outliers tend to have significant impact on the results (Hair et al., 1998) subsequent analysis were conducted to remove outliers. However, the results were nearly similar, and the cases reinstated to ensure the various groups in the sample were represented.

Table 1. Correlation of Main Factors $(\mathrm{N}=48)$

\begin{tabular}{|c|c|c|c|c|c|c|c|}
\hline Factors & 1 & 2 & 3 & 4 & 5 & 6 & 7 \\
\hline 1 Target $(M L)$ & .885 & & & & & & \\
\hline 2 Ideal learner & $.751^{* *}$ & .910 & & & & & \\
\hline 3 Ought to L2 Ir & .284 & $.491^{* *}$ & .883 & & & & \\
\hline 4 Social goals & $692^{* *}$ & $.744^{* *}$ & $.507^{* *}$ & .839 & & & \\
\hline 5 Anxiety & -.095 & .034 & $.468^{* *}$ & .143 & .932 & & \\
\hline 6 Attitude & $.816^{* \star}$ & $.800^{* *}$ & $.410^{* *}$ & $.668^{\star \star}$ & -.057 & .831 & \\
\hline
\end{tabular}


Shanthi Nadarajan, Nurul H. Hussien, Damien Mikeng

\begin{tabular}{|c|c|c|c|c|c|c|c|}
\hline Factors & 1 & 2 & 3 & 4 & 5 & 6 & 7 \\
\hline Effort & $.800^{* *}$ & $.870^{* *}$ & $.424^{* * *}$ & $.765^{* *}$ & -.016 & $.888^{* *}$ & .883 \\
\hline Possible range & $1-6$ & $1-6$ & $1-6$ & $1-6$ & $1-6$ & $1-6$ & $1-6$ \\
\hline$M$ & 5.34 & 5.18 & 4.14 & 4.82 & 3.29 & 5.07 & 5.23 \\
\hline SD & .59 & .63 & .84 & .73 & .90 & .75 & .54 \\
\hline
\end{tabular}

Note: Alpha values on diagonal, correlation values below diagonal.

$* p<.05 * * p<.01$ ( 2 tailed). Correlations using pairwise deletion of missing data.

Bivariate correlations results were consistent and significant $(p<.05)$ at $>.2$ and $<.5$ and similar to other L2 motivation research. Standardized scores for the seven factors (z scores) were used for the cluster analyses. A hierarchical cluster analyses were conducted using Ward's linkage method and squared Euclidean distance in order to obtain the most appropriate number of clusters represented in the data. Agglomeration coefficients from the hierarchical analysis were examined. The options for two to five cluster solutions were explored and the four-cluster solution was selected due to good sample representation (15$36 \%$ ). For descriptive purposes, the likelihood ratio chi-square analysis was conducted. This was to confirm that the profiles did not have uneven representation of gender distribution, $X^{2}(3)=2.564, p>0.05$, and separate ANOVAs for discipline, $F(2,75)=.031$, $p>0.05$ and age $F(2,75)=.360, p>.05$.

\section{Findings}

The results are discussed in two parts. The first part deals with a description of the different cluster groups and the second part addresses the group performance on the various criterion measures.

\section{Definition of Motivation Profiles}

The first step was to subject the various $L 2$ learners and the program related multi-item scales to hierarchical clustering to produce dendograms. Based on the visual representations of the dendograms, a four-cluster solution was used in the subsequent nonhierarchical clustering. While there were no absolute criteria for the final number, the researchers followed a common sense approach which was to get a near similar number for all groups similar to Csizer and Dornyei's (2005). The four groups showed good discriminant validity. Table 2 reports the means, standard deviation and $z$ scores for each profile. The labels used to characterize the profiles to their counterparts do not necessarily correspond to high and low levels of intelligence or proficiency in absolute terms. See Figure 1 for a representation of each profile using standardized scores.

Group 1 was labeled as motivated $(n=18)$ since the means scores were $<5$ (4.54- 4.90). This was much lower compared to Groups 3 and 4 's scores. Group 2 was labeled amotivated $(n=22)$ due to the lower target ratings (4.33). The average mean scores for the IL2 and $\mathrm{O}_{2} \mathrm{~L}_{2}$ were 4.21-3.22. Group 3 was labeled externally motivated $(n=19)$ since the mean scores for the target component (MLB) was 5.76 and other factors (5.78-4.70). The $\mathrm{O}_{2} \mathrm{~L}_{2}$ factor and SG were also higher suggesting higher instrumental motivation. Group $4(n=19)$ was labeled as self-determined/autonomous due to its equally high mean scores for the target component (5.50) and for the ideal $L_{2}$ learner (5.06). The group's $O_{2} L_{2}$ learner mean was lower compared to Groups 1 and 3 signifying less dependence on externally regulated 
variables (e.g., peer pressure and parental needs). See Figure 1 for representation of the main factor effect according to standardized scores.

Table 2. Distribution of Means, SD and Standardized Scores for Motivation Profiles Based on K-Means Analysis

\begin{tabular}{|l|c|c|c|c|c|c|c|c|c|c|c|c|}
\hline Groups(n) & \multicolumn{3}{|c|}{ Motivated Learning } & \multicolumn{3}{c|}{ Ideal L2 Learner } & \multicolumn{2}{c|}{ Ought to L2 Learner } & \multicolumn{3}{c|}{ Social Goals } \\
\hline & $\mathrm{M}$ & $\mathrm{SD}$ & $\mathrm{Z}$ & $\mathrm{M}$ & $\mathrm{SD}$ & $\mathrm{Z}$ & $\mathrm{M}$ & $\mathrm{SD}$ & $\mathrm{Z}$ & $\mathrm{M}$ & \multicolumn{1}{c|}{$S D$} & Z \\
\hline Gp1(18) & 4.90 & 0.30 & -1.23 & 4.78 & 0.24 & -0.32 & 4.59 & 0.43 & 1.18 & 4.54 & 0.51 & -1.64 \\
\hline Gp2(22) & 4.33 & 0.44 & -2.68 & 4.21 & 0.36 & -2.34 & 3.22 & 0.46 & -1.48 & 3.67 & 0.42 & -1.98 \\
\hline Gp3 (19) & 5.76 & 0.36 & 1.07 & 5.78 & 0.24 & 1.25 & 4.70 & 0.66 & 1.94 & 5.43 & 0.51 & 1.54 \\
\hline Gp4 (19) & 5.50 & 0.31 & -0.39 & 5.06 & 0.43 & -0.09 & 3.50 & 0.59 & -2.36 & 4.69 & 0.36 & -0.64 \\
\hline
\end{tabular}

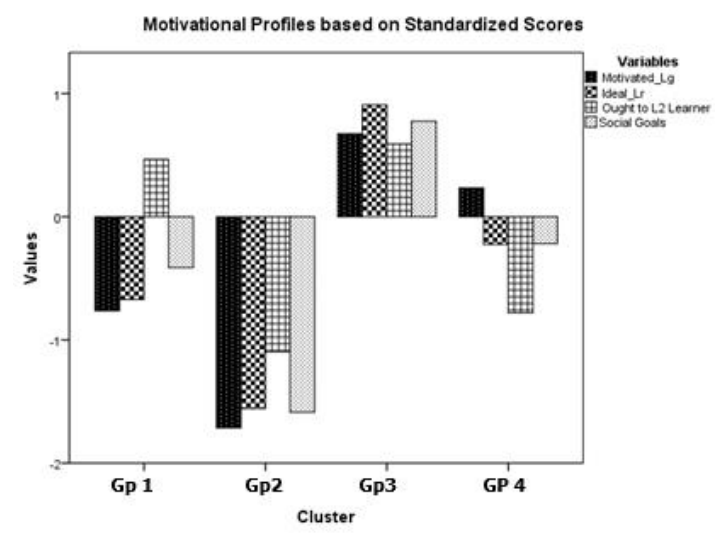

Figure 1. Main factors motivating learners

As indicated in Table 2 and Figure 1, the cluster groups for the various motivational dimensions were largely similar except Group 2. Only Groups 3 and 4 were motivated to learn. While Group 3 displayed positive mean for all dimensions, Group 4 demonstrated negative means for most dimensions except MLB but was labeled as self-determined. Possibly, with motivational variables being inter-correlated, some learners were characterized by extreme patterns. It was necessary to examine the validity of the groups by examining the combined effects within the groups for further clarity.

\subsection{Group Performance}

The mean scores for the groups were largely homogenous (Refer Table 2). The variations did not change the group analysis. The mean scores compared to the standardized scores revealed Group 3 as 1.07-1.94 points above the others. Group 4 though below the mean (0.09- 0.64) for all except $\mathrm{O}_{2} \mathrm{~L} 2$ was better than Group 1 and 2. Group 3 comprised students scoring higher than average means for all scales $(<5.5)$ except $\mathrm{O}_{2} \mathrm{~L}_{2}$ and was labeled as externally motivated learner type. Group 4's O2L2 factor and SG were below Group 3 and 1 but remaining factors were above 5 and was described as self-determined. Group 2 scored below average by 2.5 points suggesting amotivated learner types. Group 1 was motivated and scored high but the means were around 4.5 and above for the target behavior and IL2 factor. Group 1 was considered the intrinsically motivated learner type. The mean average for the IL2 factor for most groups was rather intriguing as they were below the mean for three of the groups. A one-way ANOVA for the remaining motivational scales revealed some relationship between the behaviors of Groups 1 and 2. Instead of a homogenous 
distribution for the various scales, there were differences for attitude and SG cohesion. Group 4 exceeded Groups 1 and 2 in attitude and effort. For Group 2, the differences were marked in terms of low means scores for instrumental attributes, social groups, anxiety and attitude. Overall, Groups 1, 2, and 4 were different not only in terms of motivational intensity for arriving at the target but also in terms of the structure of their motivational profile. There were marked differences for anxiety, attitude and effort between groups. This made it necessary to examine the validity of the grouping factors by substantiating the results against the criterion variables.

The one-way ANOVA with the overall scores (MI) as the dependent variable was significant, $F(3,43)=41.798, p<.005$ (see Table 3). Post hoc comparisons using Tukey HSD test means indicated the mean scores for profiles as significantly different. The similarities between the means of Groups 1 and 4 were concerning.

Table 3. Overall Means and SD for Motivated Learning Behavior based on Profiles

\begin{tabular}{lll|r|r|r}
\hline Groups & N & Mean & \multicolumn{1}{c}{ SD } & \multicolumn{1}{c}{ Minimum } & \multicolumn{1}{c}{ Maximum } \\
\hline Gp 1 & 18 & 266.11 & 14.34 & 246 & 290 \\
\hline Gp 2 & 22 & 222.33 & 13.64 & 196 & 236 \\
\hline Gp 3 & 19 & 301.42 & 19.10 & 273 & 346 \\
\hline Gp 4 & 19 & 266.38 & 11.85 & 246 & 283 \\
\hline
\end{tabular}

Gp 1- motivated; Gp 2- Amotivated; Gp 3-Externally motivated; Gp 4-self

Determined

Very High (354- 300), high (299-260), Average (259-200), Low (<199)

The analysis of variance based on mean scores for the six contributing factors (see Table 4) revealed Group 1 as recording a higher and more positive means for all factors except attitude and effort compared to Group 4. External factors like peer group, societal pressure had an effect on the anxiety level.

Table 4. Analysis of Variance: Motivational scales ( 6 points) in each cluster group

\begin{tabular}{|c|c|c|c|c|c|c|c|c|c|c|c|c|}
\hline & \multicolumn{2}{|c|}{ IL2 } & \multicolumn{2}{|c|}{ OL2 } & \multicolumn{2}{|c|}{ SG } & \multicolumn{2}{|c|}{ Anxiety } & \multicolumn{2}{|c|}{ Attitude } & \multicolumn{2}{|c|}{ Effort } \\
\hline Groups & Mean & $S D$ & Mean & $S D$ & Mean & $S D$ & Mean & $S D$ & Mean & $S D$ & Mean & $S D$ \\
\hline Gp 1 & 4.78 & 0.24 & 4.59 & 0.43 & 4.54 & 0.51 & 3.85 & 0.78 & 4.58 & 0.43 & 4.83 & 0.19 \\
\hline Gp 2 & 4.21 & 0.36 & 3.22 & 0.46 & 3.67 & 0.42 & 3.13 & 0.48 & 3.92 & 0.69 & $4 \cdot 35$ & 0.34 \\
\hline Gp 3 & 5.78 & 0.24 & 4.70 & 0.66 & 5.43 & 0.51 & 3.33 & 1.11 & 5.66 & 0.46 & $5 \cdot 72$ & $\begin{array}{l}0.2 \\
9\end{array}$ \\
\hline Gp 4 & 5.06 & 0.43 & 3.50 & 0.59 & 4.69 & 0.36 & 2.96 & 0.66 & 5.08 & 0.44 & 5.22 & 0.30 \\
\hline $\mathrm{F}$ & 44.96 & & 18.32 & & 24.96 & & 1.93 & & 23.98 & & 43.40 & \\
\hline$P$ & & 0.00 & & 0.00 & & 0.00 & & 0.14 & & 0.00 & & $\begin{array}{l}0.0 \\
0\end{array}$ \\
\hline
\end{tabular}

*The mean difference is significant at the 0.05 level

\subsection{Differences Between Groups 2 and 1,3 and 5}

The one-way MANOVA for learner scores for anxiety, attitude and effort were significant (Pillai's trace $=1.291, F(18,2004)=4.991, p<.005$, partial $\left.\Pi p^{2}=.29\right)$. Follow up univariate analysis indicated the group profiles as having a significant effect on investment at $F(3,75)$ =23.983, $P<0.01$, partial $\Pi p^{2}=.62$ and effort at $F(3,75)=43.401, P<0.01$, partial $\Pi p^{2}=43$. There were no significant differences for anxiety for all (see Table 5). 
Table 5. Univariate F, Effect size, and Profile Means, SD and Standardized Scores for anxiety, attitude and effort

\begin{tabular}{|c|c|c|c|c|c|c|c|c|c|c|}
\hline \multirow[b]{2}{*}{ Variable } & & & \multirow{2}{*}{$\begin{array}{l}\text { Gp } 1 \\
\text { Motivated }\end{array}$} & & \multicolumn{2}{|l|}{ Gp 2} & \multicolumn{2}{|l|}{$\mathrm{Gp}_{3}$} & \multicolumn{2}{|l|}{$\mathrm{Gp}_{4}$} \\
\hline & & & & & Low Motiva & & Ext. mot & tion & Self-detern & nined \\
\hline & & & $(n=18)$ & & $(n=22)$ & & $(n=19)$ & & $(n=19)$ & \\
\hline & $F(3,75$ & $\eta p^{2}$ & $M(S D)$ & $z$ & $M(S D)$ & $z$ & $M(S D)$ & $z$ & $M(S D)$ & $Z$ \\
\hline Anxiety & 1.928 & 0.116 & $\begin{array}{l}3.84 \\
(0.78)\end{array}$ & -0.23 & $3.12(0.48)$ & 1.43 & $\begin{array}{l}3.32 \\
(1.11)\end{array}$ & -0.7 & $2.96(0.66)$ & 0.13 \\
\hline Attitude & $23.983 * *$ & 0.621 & $\begin{array}{l}4.5^{8} \\
(0.42)\end{array}$ & 0.97 & $3.91(0.69)$ & 0.96 & $\begin{array}{l}5.66 \\
(0.46)\end{array}$ & 0.7 & $\begin{array}{l}5.08 \\
(0.44)\end{array}$ & -0.64 \\
\hline Effort & $43.401 * *$ & 0.747 & $\begin{array}{l}4.83 \\
(0.19)\end{array}$ & -2.16 & $\begin{array}{l}4.35 \\
(0.33)\end{array}$ & 1.06 & $\begin{array}{l}5.71 \\
(0.28)\end{array}$ & 0.74 & $5.23(0.55)$ & -0.7 \\
\hline
\end{tabular}

Note: $* * p<.01 ;$ Cluster differences $(p<.05)$ based on pairwise comparison of estimated marginal means.

Analysis are based on participants with complete data $(n=78)$

In terms of multiple comparisons, the mean scores for attitude and effort were significant. Group 2 demonstrated positive mean for all three variables. The $z$ scores were below average for Group 1. Group 3's efforts were above the median but anxiety was below the mean average (see Figure 2). Group 2 had a higher level of anxiety compared to all others. A similar conclusion can be for both Groups 2 and 3 which reflected higher attitude and efforts.

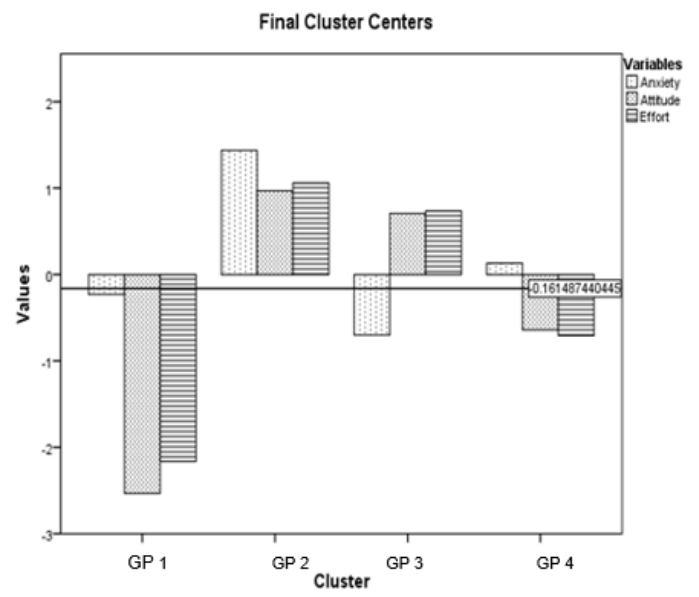

Figure 2. Profile differences using standardized scores for anxiety, attitude and effort Horizontal line denotes median

Group 3 was the externally motivated group while Group 2 was the amotivated group. So, how do we interpret this seemingly contradictory situation?

The one-way MANOVA for socio psychological factors (externally regulated motives) for L2 learning experience (e.g. positive experience, interest, teacher factor), investment (e.g. willing to take another English course, usefulness for lifelong learning), and appreciation of 
learner ethnicity (e.g. recognition of local culture) were significant (Pillai's trace $=.820, F$ ( 9 , $132)=5.518, p<.005$, partial $\left.\eta p^{2}=.28\right)($ see Table 6$)$.

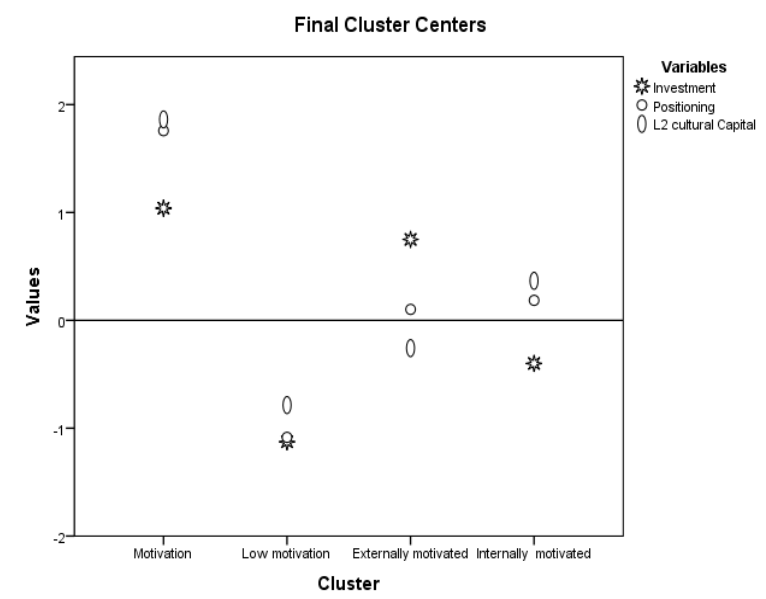

Figure 4. Profile differences for student positioning, investment and L2 cultural capital

Follow up univariate analysis indicated the group profiles as having a significant effect on investment at $F(3,75)=35.965, P<0.005$, partial $\Pi p^{2}=.71$ and positioning at $F(3,75)=8.464$, $P<0.005$, partial $\eta p^{2}=.36$. There was a significant effect for L2 cultural capital at $F(3,75)$ $=2.726, \mathrm{P}<0.05$, partial $\prod \mathrm{p}^{2}=.157$ (see Table 6).

Table 6. Univariate F, Effect Size and Profile Means, SD and Std. Scores for ss positioning and investment Variables

\begin{tabular}{|c|c|c|c|c|c|c|c|c|c|c|}
\hline Groups & & & $\begin{array}{l}\text { GP } 1 \\
(n=18)\end{array}$ & & $\begin{array}{l}\text { GP } 2 \\
(n=22)\end{array}$ & & $\begin{array}{l}\mathrm{GP}_{3} \\
(n=19)\end{array}$ & & $\begin{array}{l}\text { GP 4 } \\
(n=19)\end{array}$ & \\
\hline Variable & $F(9,132)$ & $\eta p^{2}$ & $M(S D)$ & $Z$ & $M(S D)$ & $Z$ & $M(S D)$ & $Z$ & $M(S D)$ & $Z$ \\
\hline Investment & $35.965 * *$ & 0.71 & $\begin{array}{l}24 \\
(1.73)\end{array}$ & 1.04 & $\begin{array}{l}21.17 \\
(1.47)\end{array}$ & -1.13 & $\begin{array}{l}28.79 \\
(1.75)\end{array}$ & 0.75 & $\begin{array}{l}26.14 \\
(1.79)\end{array}$ & -0.4 \\
\hline Positioning & $8.463^{* *}$ & 0.366 & $\begin{array}{l}21.89 \\
(2.26)\end{array}$ & 1.76 & $\begin{array}{l}17.50 \\
(1.76)\end{array}$ & -1.09 & $\begin{array}{l}24.21 \\
(3.78)\end{array}$ & 0.1 & $\begin{array}{l}21.07 \\
(2.46)\end{array}$ & 0.19 \\
\hline culture & $2.726 *$ & 0.157 & $\begin{array}{l}20.78 \\
(4.09)\end{array}$ & 1.86 & $\begin{array}{l}18.50 \\
(2.43)\end{array}$ & -0.79 & $\begin{array}{l}22.11 \\
(3.56)\end{array}$ & - & $\begin{array}{l}19.79 \\
(3.26)\end{array}$ & 0.37 \\
\hline
\end{tabular}

Groups 1 and 3 were more likely to invest in the learning process based on the positive positioning of their L2 experience. Both Groups 2 and 4 were unlikely to invest in future language courses.

\section{Discussion}

This study used cluster analysis to: a) investigate the dominant motivation dimensions affecting $L 2$ sub communities in an L2 setting and (b) broaden the scope of positioning and investment often discussed in identity through a psychological construct. It also aimed to address rising demands for a more inclusive curriculum from a Malaysian university perspective. The findings will be discussed in terms of theoretical and practical implications.

\subsection{Dominant Motivation Dimensions}

The study provided evidence for Dornyei's tripartite model with the IL2 self, O2 22 self, and learning experiences serving as main predictors of learner success (Dornyei \& Chan, 2013) for the externally motivated learner types and Self -determined learner types. All L2 sub- 
communities except the amotivated group had a positive experience of the course. Both motivated and externally motivated groups recorded positive ideal learner image and this is due to the desire to secure good grades, which is reflective of real $L 2$ learning needs. As Csizer and Dornyei's (2005) mentioned, "learners do not study English because they are motivated to do so, but because it is part of general education" (p.649). This is applicable to all L2 learners. With English being used as medium of instruction and the course being compulsory, the learners had to have a good grasp of English. Then again, the amotivated and externally motivated learners demonstrated positive means for attitude and effort. This contradictory situation can be due to learners' expectations for English courses to be 'safe' and anxiety free. Any curricula revisions to get $L 2$ learners increase their efforts can be risky as it would mean learners having to work harder and this can interfere with their core assignments and academic goals. The alternative would to engage and involve learners in active learning online activities. Exceptions will be the self-determined learner types who will complete the task well irrespective of teacher, peers and grade requirement.

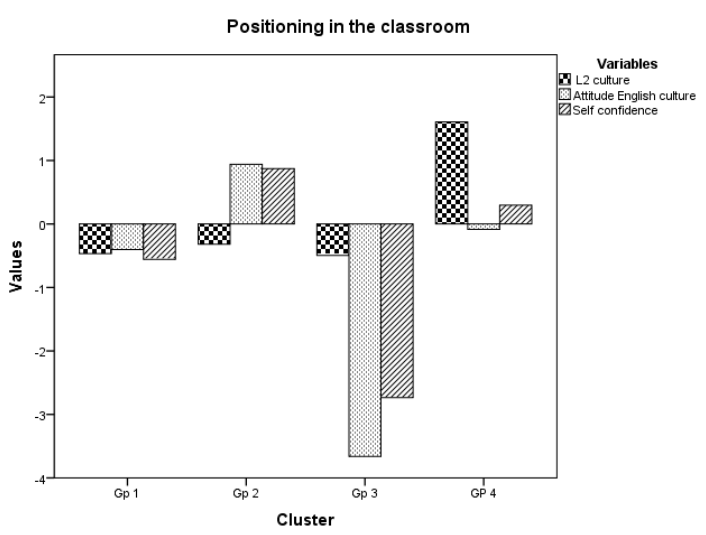

Figure 6. Positioning in the classroom

All groups except the self-determined learner types were unimpressed by the L2 cultural readings. This suggest a mismatch between $L 2$ sub communities' needs and the syllabus. The amotivated group demonstrated a positive attitude towards the English culture. The linguistic complexity and 'foreignness' of the $L 2$ reading materials could be some reasons. The self- determined learner types appreciated the in-class readings. The Self- determined learners did well not because of the classroom environment but due to the positive image of their ideal learner self cum self -regulated behavior. For confidence, both groups 2 and 4 demonstrated positive scores. The positive attitude towards the L2 culture could had a positive effect on the amotivated group's confidence. The fact that the amotivated group and the self-determined group demonstrated similar attitudes towards the classroom experience is interesting. Further breakdown based on program yielded additional information (refer Figure 6). 


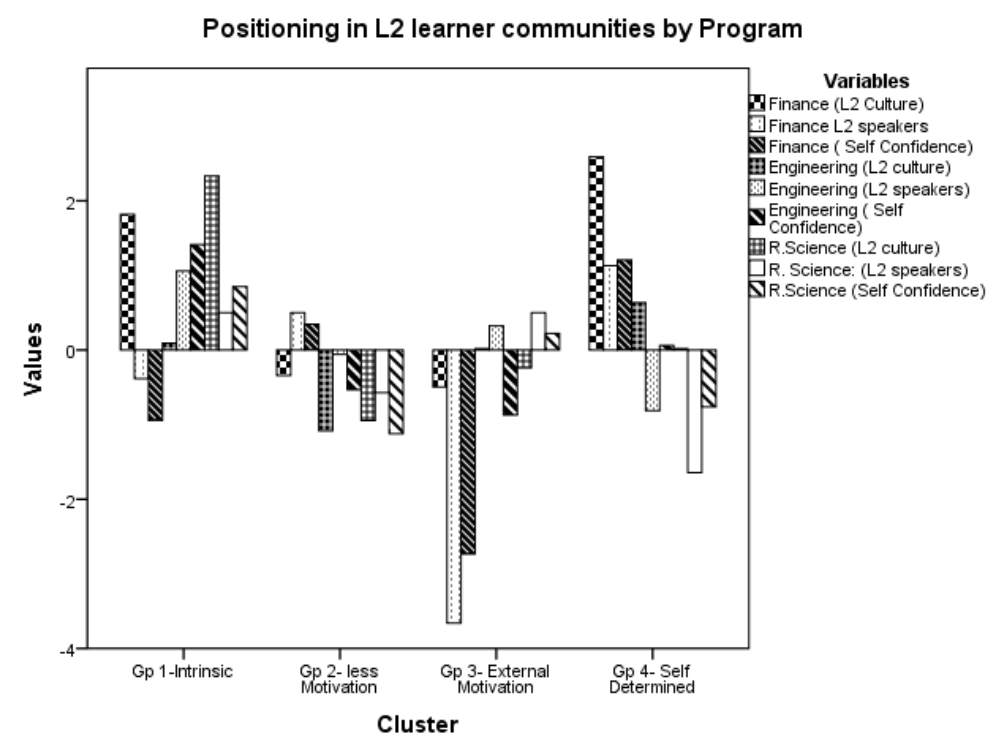

Figure 7. Positioning in L2 learner communities by programs

A breakdown of the clusters and variables programs based on Z scores revealed that only the motivated and self-determined learner types viewed the $L 2$ culture positively. However, there were differences within each learner types as well. Most L 2 communities except those from Finance valued the in-class reading resources. The majority were unimpressed by the various positioning traits and this is worrying. At the micro level there were difference within each learner sub-community. The finance students from the amotivated group and Engineering students from the externally motivated groups viewed the L2 speakers and self-confidence positively. Positive positioning as ethnic minorities is said to inspire L2 learners to develop self-confidence to draw on their ethnic identity to negotiate other desirable identities such as individual with special knowledge on specific aspects (Lee, 2008). However, the same could not be said for the L2 learners from resource science programs. Courses that overlook the learners learning experience can be a cause for the negative positioning.

\subsection{Positioning and Investment}

ELLs positioning and investment in the L2 classrooms can be explored alongside the concept of citizen of the world or transnational identity (Higgins, 2011). Since only Malay speakers were selected, various confounding variables were minimized. The learners had the opportunity to use Malay. Despite their dominant language advantage, some L2 communities chose to use and speak in English due to instrumental and integrative needs. Being proficient, many viewed themselves as 'elite speakers' in an imagined global community. The motivated learners had a positive view of their language skills and were confident of sharing their experiences in classes with other L 2 communities. This finding is similar to Cervatiuc's (2009) where multilingual adults adhered to an imagined multi competent community to boost their self-confidence and reach out to other L2 communities in real life. Then again, motivation studies have shown that that extroverted learners have an advantage when it comes to criterion measures in "communicative language" learning situations. The caveat being as Ellis (2004) mentions, "Extraverts ... 
(tend to be) ... generally more fluent than introverts in both the L1 and L2 (but) they were not, however, necessarily more accurate in their L2" (p. 532). Thus it should not come as surprise if English debates in Malaysia continue to sensationalize Malay (Malaysian learners included) lack of ability to use English accurately. The disinterest in the L2 readings suggest some level of discomfort with an English only classroom. Given the plural setting of Malaysia, where code mixing is common in classrooms, expecting learners to feel selfconfident of their language performance might be a tall order. This could also explains why a large number $(71 \%)$ of $L 2$ learners did not fall into the self-regulating category. The course did not create anxiety and being proficient students, the English course failed to challenge. As Ellis (2004) states, it is simplistic to assume that less anxiety is better. In settings with minimal anxiety, there is greater likelihood of students not seeing the need to perform optimally, attending classes or investing in future courses since grades fail to discriminate between the good and better students.

Placed against findings from SLA motivation studies, the findings align with $\mathrm{Yu}$, Brown and Stephens' (2018) suggestion, that the "ideal L2 learner self" image will continue to serve as the dominant motivator for $L 2$ learners. At the macro level, this study is no different. $L 2$ learners regardless of ethnicity take English to "find good jobs", "study abroad" and for "professional development". Differences however are at the micro level i.e. attitude and self-confidence. There is waning interest in using $L 2$ culture and reading resources. This contradicts what is expected of University students. Courses that overlook learners' first language experience and cultural resources risk excluding learners from feeling a sense of belonging. In Malaysia, English despite being a second language is not widely used by some communities. The students valued English, but as adult learners there was the affective filter which probably prevented learners from performing optimally. Disinterest in the readings and prolonged hesitation to invest in the learning process can short circuit future prospects of communities benefitting from this linguistic capital. In Asia, some ELLs learn English for the symbolic value rather than functional value and know that English would not bring much chance in their lives. The ability to use English (in South East Asia) however, may mean authority in their daily life, access to internet resources and access to a wider range of symbolic and materials resources (Norton, 2016) but at universities this is realized through self-determination and self-confidence. By including the learners' first language experiences and encouraging learners to lead through active learning, instructors provide scaffolding and support for learners to take interest in the language resource and become valued members of their community. There are limitations to this study though. While the study was situation-specific and results stable, the learners comprised only proficient Malay undergraduates. This study excluded the other L2 communities in multilingual Malaysia. Future studies can benefit from a wider population with differing proficiencies.

\section{Conclusion}

Overall, this study provided an alternative means of exploring ELLs motivation in classrooms. It used a psychological construct to investigate learner types and extended the findings to a sociocultural perspective. It has also framed the globalization versus nationalization debate in Malaysia differently. The study revealed that Malay learner like all ELLS value the English classroom but are limited by self-confidence and cultural preference. Like most Asian communities, the learner's identity is strongly related to the L1 culture and experiences. Failure to integrate this need for greater inclusiveness can limit even self- 
determined L2 learners. Universities need to recognize the need for inclusivity alongside IR4 skills and work towards making the courses more relevant and personalized to meet learner types.

\section{References}

Achugar, M. (2009). Constructing A Bilingual Professional Identity In A Graduate Classroom. Journal of Language, Identity, And Education, 8(2-3), 65-87. doi.org/10.1080/15348450902848387

Behari-Leak, K. \& Goitsione, M. (2019) Disrupting Metaphors Of Coloniality To Mediate Social Inclusion In The Global South, International Journal For Academic Development, 24:2, 135-147, doi: 10.1080/1360144X.2019.1594236

Campbell, J. (2018). English Language And An Inclusive Malaysia. $3 L$ : The Southeast Asian Journal Of English Language Studies, 24(3), 206 - 219. doi.Org/10.17576/3L-2018-240315

Cervatiuc, A. (2009). Identity, Good Language Learning, And Adult Immigrants In Canada. Journal Of Language, Identity, And Education, 8(4), 254-271.

Chew, P. G. L. (2010). Linguistic Capital, Study Mothers, And Globalization. In V. Vaish (Ed.), Globalization of Language And Culture In Asia (Pp. 82-105). London, England: Continuum.

Clement, R., Dornyei, Z., \& Noels, K. A. (1994). Motivation, Self-Confidence, And Group Cohesion In The Foreign Language Classroom. Language Learning, 44(3), 417-448.

Csizer, K., \& Dornyei, Z. (2005). Language Learners' Motivational Profiles And Their

Motivated Learning Behavior. Language Learning, 55, 613-659. doi:10.1111/J.0023-8333.

Dornyei, Z. (2001). New Themes And Approaches In Second Language Motivation Research. Annual Review Of Applied Linguistics, 21, 43-59.

Dornyei, Z. (2005). The Psychology Of The Language Learner: Individual Differences In

Second Language Acquisition. Mahwah, NJ: Erlbaum.

Dornyei, Z. (2009). The L2 Motivational Self-System. In Z. Dornyei \& E. Ushioda (Eds.),

Motivation, Language Identity And The L2 Self (Pp. 9-42). Bristol, UK: Multilingual Matters.

Dornyei, Z., \& Chan, L. (2013). Motivation And Vision: An Analysis Of Future L2 Self-Images,

Sensory Styles, And Imagery Capacity Across Two Target Languages. Language Learning, 63(3), 437-462. doi=10.1.1.683.4275

Dornyei, Z., \& Csizer, K. (2002). Some Dynamics Of Language Attitudes And Motivation: Results Of A Longitudinal Nationwide Survey. Applied Linguistics, 23(4), 421-462.

Ellis, R. (2004). Individual Differences In Second Language Learning. In A. Davies \& C. Elder (Eds.), The Handbook Of Applied Linguistics (Pp. 25-551). Malden, MA \& Oxford: Blackwell Publishing.

Giroir, S. (2014). Narratives Of Participation, Identity, And Positionality: Two Cases Of Saudi Learners Of English In The United States. TESOL Quarterly, 48(1), 34-56.

Hair, J.F. Anderson, R.E. Tatham, R.L., \& Black, W.C. (1998). Multivariate Data Analysis. Upper Saddle River, NJ: Prentice Hall.

Henry, D. B., Tolan, P. H., \& Gorman-Smith, D. (2005). Cluster Analysis In Family Psychology Research. Journal Of Family Psychology, 19(1), 121-132. doi: 10.1037/08933200.19.1.121

Hopf, T. (2000). Constructivism All The Way Down. International Politics, 37(3), 369-378. 
Lee, S. K., Lee, K. S., Wong, F. F., \& Ya'acob, A. (2010). The English Language And Its Impact On Identities Of Multilingual Malaysian Undergraduates. GEMA Online ${ }^{\circledR}$ Journal Of Language Studies, 10(1), 87-101.

Noels, K. A., Pelletier, L. G., Clément, R., \& Vallerand, R. J. (2000). Why Are You Learning A Second Language? Motivational Orientations And Self-Determination Theory. Language Learning, 50(1), 57-85. doi: 10.1111/0023-8333.00111

Norton, B. (2016). Identity And Language Learning: Back To The Future.TESOL Quarterly, 50(2), 475-479.

Papi, M. (2010) The L2 Motivational Self-System, L2 Anxiety, And Motivated Behavior: A

Structural Equation Modeling Approach. System, 38, 467- 479. doi:0.1016/J.System.2010.06.011.

Yu, J., Brown, G. T., \& Stephens, J. M. (2018). Retrospective Case Studies Of Successful Chinese Learners Of English: Continuity And Change In Self-Identities Over Time And Across Contexts. System, 72, 124-138. 
Shanthi Nadarajan, Nurul H. Hussien, Damien Mikeng 